Clinical Research

\title{
Potential role of the melanocortin signaling system interference in the excess weight gain associated to some antiretroviral drugs in people living with HIV
}

\author{
Pere Domingo $^{1} \cdot$ Francesc Villarroya ${ }^{2} \cdot$ Marta Giralt $\mathbb{D}^{2} \cdot$ Joan Carles Domingo ${ }^{2}$
}

Received: 19 September 2019 / Revised: 22 January 2020 / Accepted: 7 February 2020 / Published online: 20 February 2020

(C) Springer Nature Limited 2020

\begin{abstract}
Exposure to some antiretroviral drugs, especially integrase strand transfer inhibitors (INsTI)-based combination antiretroviral therapy (cART) has been associated with weight gain in people living with HIV (PLWH) exceeding what would be a "return to health" phenomenon. Notwithstanding the fact that weight gain and obesity are multifactorial, the common epidemiological link in PLWH is INsTI-based cART. Here, we postulate that interference with the melanocortin system (MCS) functioning by INsTI plays an essential role in excess weight gain and obesity in PLWH, similar to disturbances caused by melanocortin receptor (MCR) mutations in the general population and by antipsychotic therapy in psychiatric patients.
\end{abstract}

INsTI-based antiretroviral regimens are the most used in high-income countries [1]. DTG will be or has already been incorporated into the national treatment guidelines of almost 60 low-medium income countries, and the PEPFAR recommended the introduction of TDF/3TC/DTG in its focus countries which in 2021 will be taken by $\sim 15$ million PLWH [2]. Lately, the use of INsTI has been associated with weight increase and clinical obesity. The WHO defines obesity as abnormal or excessive fat accumulation that presents a risk to health, and presently represents an epidemic associated with decreased life expectancy [3]. The widespread use of INsTI-based regimes may fuel an epidemic of weight gain and obesity in PLWH, leading to the intersection of obesity and HIV burdens.

\section{Integrase strand transfer inhibitor-associated weight gain}

The initiation of cART is usually associated with weight increase attributed to a "return to health" event. Starting

Pere Domingo

pdomingo@santpau.cat

1 Department of Infectious Diseases, Hospital de la Santa Creu i Sant Pau, Institut de Recerca del Hospital de la Santa Creu i Sant Pau, Barcelona, Spain
cART before the INsTI era led to weight increase ranging from 1.8 to $2.7 \mathrm{~kg}$ in one year and $4.8 \mathrm{~kg}$ in 144 weeks [4]. In general, weight increase associated with lower mortality in underweight or normal-weight patients, without benefit for overweight and obese patients due to increased rates of diabetes and cardiovascular disease [5]. Pivotal INsTI clinical trials did not report weight changes, but fat substudies of ACTG 5247 and NEAT 01 pointed to higher weight gain, mostly in visceral adipose tissue, in RAL arms [6]. In two recent open-label, RCT in Africa, DTG-based regimes associated with significantly higher weight gain and incident clinical obesity compared with efavirenz-based regime [7, 8]. A recent pooled analysis of eight Gileadsponsored RCT confirmed the association of INsTI with higher weight gain than PI or NNRTI [9]. Switching from PI-based to DTG-based regime was associated with significantly higher weight gain after 48 weeks [9].

Evidence from observational and cohort studies has accumulated since 2017, indicating INsTI exposure as the common trait [10]. In the last CROI (Seattle, March 2019), a themed discussion session reported evidence of excess

2 Departament de Bioquímica i Biomedicina Molecular and Institut de Biomedicina (IBUB), Universitat de Barcelona, CIBER Fisiopatología de la Obesidad y Nutrición,

Barcelona, Spain 
weight gain in PLWH, both starting and switching to INsTIbased cART [10]. An INsTI-related weight gain hierarchy was proposed with DTG and bictegravir (BIC) associated with the highest increase $[9,10]$. Factors associated with weight increase were the NRTI backbone, mainly when included TAF, gender (higher increase in females), ethnicity (higher increase in blacks), and baseline CD4 count and viral load $[9,10]$. Furthermore, exposure to TAF in naïve and patients switching from TDF or to abacavir in patients switching from old NRTI or TDF associated with weight increase $[9,10]$.

\section{Melanocortin system function: role in weight gain and obesity}

The POMC/MC4R system is the most potent physiological control mechanism of food intake behavior and metabolic energy balance in mammals. Alterations in the functioning of this system are known to cause obesity. The ARC in the hypothalamus contains POMC/CART neurons, which express the POMC gene and produce $\alpha-\mathrm{MSH}$, which locally targets MC4R and MC3R and elicits a robust anorexigenic response through inhibitory actions upon the NPY neurons, also in the ARC, which are orexigenic, and through actions on second-order neurons (Fig. 1). Naturally occurring inhibition of the MC4R through AgRP increases food intake and promotes fat deposition. Conversely, the stimulation of MC4R by $\alpha$-MSH reduces food intake and promotes peripheral energy expenditure, together fostering an overall negative energy balance [11]. External signals, leptin, and insulin suppress food intake, and activate $\alpha$-MSH synthesis to target MC4R, whereas fasting leads to $\alpha-\mathrm{MSH} / \mathrm{MC} 4 \mathrm{R}$ signaling inhibition, eliciting a hunger feeling (Fig. 1).

MC4R mutations cause monogenic obesity, and children heterozygous or homozygous for loss-of-function mutant alleles of the MC4R gene develop early-onset obesity [12]. Distinct large-scale genome-wide association study analysis unveiled MC4R polymorphic gene variants associated with weight gain [12]. Pharmacological activators of MC4R are used to treat obese patients with MC4R genetic defects, and recently approved drugs for obesity (bupropion and naltrexone) activate the POMC system [13]. Conversely, MC4R antagonists or inverse agonists to treat anorexia cause increased food intake in animal models [13].

Malfunction of the MCS may also be acquired. Antipsychotic agents have been associated with weight gain [14]. Olanzapine increased food intake and body weight in female rats together with an increase in NPY and AgRP (orexigenic) and reduction of POMC mRNA levels (anorexigenic) in the ARC [14]. Ghrelin, an orexigenic hormone secreted from the stomach, potently upregulated

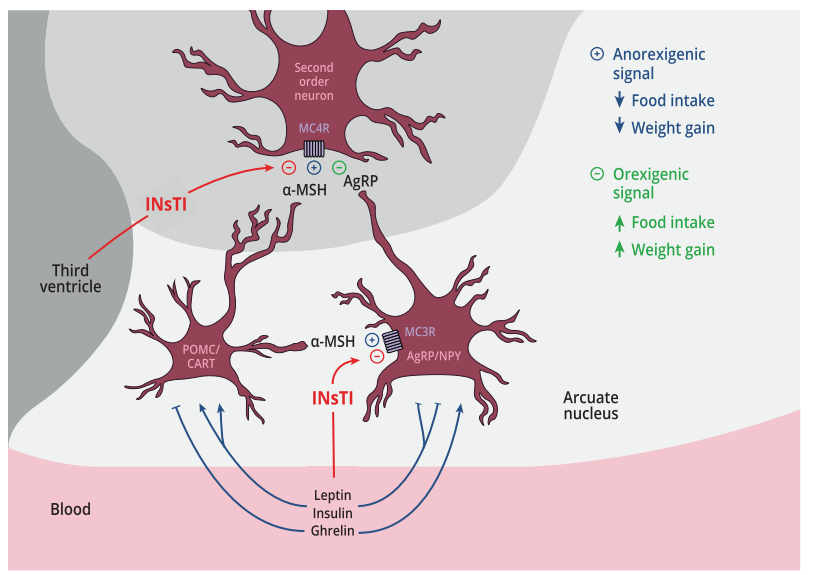

Fig. 1 Schematic representation of the potential interference of INsTI on the hypothalamic control of food intake and energy homeostasis. Alpha-MSH, released by POMC/CART hypothalamic neurons, target MC4R receptors at second-order neurons, thus eliciting an anorexigenic response. $\alpha-\mathrm{MSH}$ also acts upon MC3R receptors at hypothalamic AgRP/NPY neurons. This leads to the inhibition in the release of the orexigenic neuropeptides NPY and AgRP, this last one capable of eliciting orexigenesis through interfering MC4R signaling at second-order neurons. Insulin and leptin inhibit AgRP/NPY neurons and activate POMC/CART neurons, whereas ghrelin does reciprocal effects. INsTI may potentially interfere on $\alpha$-MSH action through MC4R and MC3R and thereby cause abnormal orexigenesis and weight gain. INsTI Integrase strand transfer inhibitor, POMC/CART Proopiomelanocortin/cocaine- and amphetamine-regulated transcript, AgRP/NPY Agouti-related protein/neuropeptide Y, $\alpha-\mathrm{MSH}$ alphamelanocyte stimulating hormone, MC3R melanocortin-3 receptor, MC4R melanocortin-4 receptor.

in olanzapine-treated female rats, leading to hyperphagia and weight gain [14].

Scarce studies have explored the MCS function in PLWH. $\alpha$-MSH plasma levels are increased in PLWH, especially in advanced infection [15]. NPY has higher immunoreactivity in CSF and plasma of PLWH relative to uninfected controls [15]. Notably, in vitro, DTG caused inhibition of $\alpha$-MSH binding to MC4R by $64 \%$. Remarkably, INsTI achieve CSF therapeutic concentrations, and the region of the ARC lacks blood-brain barrier [10].

\section{Hypothesis}

Since current cART often includes the combination of INsTI with two NRTI, and since excess weight gain has been described predominantly in INsTI-exposed patients, we hypothesize that INsTI plays a crucial role in the pathogenesis of overweight or clinical obesity in PLWH exposed to these drugs. We propose that interference by INsTI of the MCS function, leading to orexigenic response, is the mechanism responsible (Fig. 1), causing similar disturbances to those observed with MC4R mutations or antipsychotic therapy [12, 14]. 
At least four potential mechanisms could produce such induction of orexigenic response by INsTI. The first would be blocking the MC4R (Fig. 1). DTG, at $C_{\max }$ concentration, inhibits the binding of radiolabeled $\alpha-\mathrm{MSH}$ to MC4R by $64 \%$ [10]. This mechanism would inactivate the anorexigenic arm of the melanocortin system, instigating an orexigenic response. Prediction of INsTI binding to MC4R (structural superposition) derives from the presence of halogen-substituted ring in selective MC4R agonists, a feature shared by DTG and bictegravir (Gelpi JL, own data).

The second mechanism would be upregulating NPY secretion, NPY receptors, or both leading to hyperactivation of the system's orexigenic arm (Fig. 1). Plasma and CSF levels of NPY in PLWH were increased concerning to those of uninfected controls [15].

The third mechanism could be inhibiting the binding of $\alpha-\mathrm{MSH}$ to MC3R of NPY/AgRP neurons, avoiding NPY repression caused by $\alpha-\mathrm{MSH}$ and thus inducing feeding behavior [16].

A potential fourth mechanism could be through peripheral signaling to POMC/CART and NPY neurons by ghrelin or leptin or its receptors. However, no evidence exists of differences in plasma levels of these signals in the absence of metabolic or fat disturbances in cART-treated PLWH [17].

NRTI may contribute to this process through additionally unveiled mechanisms [9, 10]. However, the use of INsTI seems to be the essential factor since other cART regimes have not been consistently associated with excess weight gain. Overweight and obesity in PLWH is, like in the general population, a multifactorial process, in which INsTI and perhaps NRTI play a harmful role.

\section{Testing the hypothesis}

Different types of studies would be complementary to test this hypothesis. First, prospective clinical studies should define and validate a clinically meaningful threshold of what a significant weight gain is in cART-treated PLWH. This threshold should then be applied to RCT and observational studies. For weight-management therapies, the US FDA deems a $5 \%$ weight loss to be clinically significant [18]. Conversely, if a treatment increases weight by $5 \%$ or more, this too may be clinically significant. The contribution of antiretroviral drugs, particularly INsTI, to excess weight gain, double-blind RCT should be clarified through head-to-head comparisons between the weight gainassociated drug and another with known neutral effects. The potential contribution of NRTI may be seen in factorial designs. Switching RCT may display not only the responsibility of a drug but also the reversibility of the gained adiposity. These studies must include body composition substudies to define whether fat deposition is generalized or has a preference for a particular depot.

Substudies about MCS function in RCT, looking at plasma and CSF biomarkers, would be illuminating. The contribution of genetics must be explored, gaining insights from MCR polymorphisms associated with obesity [12]. At a peripheral level, the effects of INsTI on different adipose depots should be determined. The specific tissue pharmacodynamics of each INsTI will most likely be different and thus may cause different effects, if any, on different cell types of the depot. Invasive procedures, such as adipose tissue biopsies, would be instrumental for that purpose [19].

Second, studies in vitro using MC4R and MC3Rexpressing brain cells will assess in a cell-autonomous manner the potential interference of INsTI and other antiretrovirals upon $\alpha$-MSH mediated actions. Human adipocyte in vitro studies would be complementary to ex vivo samples and would explore any potential peripheral effects of INsTI and other antiretrovirals on the differentiation, metabolic, and secretory functions of human adipocytes in a tightly controlled environment [20].

Third, animal studies will profit from the possibility of more invasive research concerning human studies. Research should determine the effects of mice treated with different INsTIs. Distinct mouse models may be employed, from models of enhanced adiposity by exposure to obesogenic diets to transgenic mice expressing part of the HIV genome bearing signs of HIV-associated environment in vivo [21]. Food intake, body weight, adiposity acquisition, and energy expenditure pattern in animal models in response to INsTI can be done using comprehensive monitoring system cages. Animal models would be illuminating thanks to unrestricted access to blood, adipose depots, brain and hypothalamus to elucidate the functional status of the MCS.

Funding This work has been partially funded by Fondo de Investigaciones Sanitarias (FIS PI13/0796, PI14/0700, PI14/ 0063, PI016/ 0503, PI17/0420 and PI17/0498), Ministerio de Sanidad, Politica Social e Igualdad (EC11-293), and Programa de Suport als Grups de Recerca AGAUR (2014 SGR 250, 2017 SGR 948).

Author contributions All authors get involved in the design of the hypothesis. All authors coordinated and oversighted the development and testing of the hypothesis. All authors participated in data interpretation. The paper was drafted by all authors. All authors provided input to the report and approved the final version of the paper.

\section{Compliance with ethical standards}

Conflict of interest The authors declare that they have no conflict of interest.

Publisher's note Springer Nature remains neutral with regard to jurisdictional claims in published maps and institutional affiliations. 


\section{References}

1. Panel on Antiretroviral Guidelines for Adults and Adolescents. Guidelines for the use of antiretroviral agents in adults and adolescents with HIV. Department of Health and Human Services. http://www.aidsinfo.nih.gov/ContentFiles/Adulta ndAdolescentGL.pdf. Accessed 8 May 2019.

2. Vitoria M, Hill A, Ford N, Doherty M, Clayden P, Venter F, et al. The transition to dolutegravir and other new antiretrovirals in lowincome and middle-income countries: what are the issues? AIDS. 2018;32:1551-61.

3. Blüher T. Obesity: global epidemiology and pathogenesis. Nat Rev Endocrinol. 2019;15:288-98.

4. Erlandson KM, Taejaroenkul S, Smeaton L, Gupta A, Singini IL, Lama JR, et al. A randomized comparison of anthropomorphic changes with preferred and alternative efavirenz-based antiretroviral regimens in diverse multinational settings. Open Forum Infect Dis. 2015;2:ofv095.

5. Achhra AC, Mocroft A, Reiss P, Sabin C, Ryom L, de Wit S, et al. Short-term weight gain after antiretroviral therapy initiation and subsequent risk of cardiovascular disease and diabetes: the D:A:D study. HIV Med. 2016;17:255-68.

6. Bernardino I, Mocroft A, Wallet C, de Wit S, Katlama C, Reiss P, et al. Body composition and adipokines changes after initial treatment with darunavir-ritonavir plus either raltegravir or tenofovir disoproxil fumarate-emtricitabine: a sub-study of the NEAT001/ ANRS 143 randomised trial. PLoS ONE. 2019;14:e0209911.

7. The NAMSAL ANRS 12313 Study Group, Kouanfack C, Mpoudi-Etame M, Omgba Bassega P, Eymard-Duvernay S, Leroy $\mathrm{S}$, et al. Dolutegravir-based or low-dose efavirenz-based regimen for the treatment of HIV-1. N Engl J Med. 2019;381:816-26.

8. Venter WDF, Moorhouse M, Sokhela S, Fairlie L, Mashabane N, Masenya $\mathrm{M}$, et al. Dolutegravir plus two different prodrugs of tenofovir to treat HIV. N Engl J Med. 2019;381:803-15.

9. Sax PE, Erlandson KM, Lake JE, McComsey GA, Orkin C, Esser $\mathrm{S}$, et al. Weight gain following initiation of antiretroviral therapy: risk factors in randomized comparative clinical trials. Clin Infect Dis. 2019 pii: ciz999. https://doi.org/10.1093/cid/ciz999.

10. Hill A, Waters L, Pozniak A. Are new antiretroviral treatments increasing the risks of clinical obesity? J Virus Erad. 2019;5:41-3.

11. Voss-Andreae A, Murphy JG, Ellacott KT, Stuart RC, Nillni EA, Cone $\mathrm{RD}$, et al. Role of the central melanocortin circuitry in adaptive thermogenesis of brown adipose tissue. Endocrinology. 2007;148:1550-60.
12. Loos RJ, Lindgren CM, Li S, Wheeler E, Zhao JH, Prokopenko I, et al. Common variants near MC4R are associated with fat mass, weight and risk of obesity. Nat Genet. 2008;40:768-75.

13. Fleming KA, Ericson MD, Freeman KT, Adank DN, Lunzer MM, Wilber SL. et al. Structure-activity relationship studies of a macrocyclic AGRP-mimetic scaffold c[Pro-Arg-Phe-PheAsn-Ala-Phe-DPro] yield potent and selective Melanocortin-4 receptor antagonists and Melanocortin-5 receptor inverse agonists that increase food intake in mice. ACS Chem Neurosci. 2018;9:1141-51.

14. Dent R, Blackmore A, Peterson J, Habib R, Kay GP, Gervais A, et al. Changes in body weight and psychotropic drugs: a systematic synthesis of the literature. PLoS ONE. 2012;7:e36889.

15. Malessa R, Heimbach M, Brockmeyer NH, Hengge U, Rascher W, Michel MC. Increased neuropeptide Y-like immunoreactivity in cerebrospinal fluid and plasma of human immunodeficiency virus-infected patients: relationship to HIV encephalopathy. J Neurol Sci. 1996;136:154-8.

16. Girardet C, Marks DL, Butler AA. Melanocortin-3 receptors expressed on agouti-related peptide neurons inhibit feeding behavior in female mice. Obesity. 2018;26:1849-55.

17. McFarlane SI, Mielke MM, Uglialoro A, Keating SM, Holman S, Minkoff $\mathrm{H}$, et al. Ghrelin, amylin, gastric inhibitory peptide and cognition in middle-aged HIV-infected and uninfected women: the women's interagency HIV study. J Neurol Neurophysiol. 2017;8:413.

18. Food and Drug Administration (USA). Guidance for industry. Development of products for weight management. 2007. www. fda.gov/downloads/Drugs/Guidances/ucm071612.pdf. Accessed April 2019.

19. Domingo P, Gutierrez M del M, Gallego-Escuredo JM, Torres F, Mateo MG, Villarroya J, et al. A 48-week study of fat molecular alterations in HIV naive patients starting tenofovir/emtricitabine with lopinavir/ritonavir or efavirenz. J Acquir Immune Defic Syndr. 2014;66:457-65.

20. Moure R, Domingo P, Gallego-Escuredo JM, Villarroya J, Gutierrez M del M, Mateo MG, et al. Impact of elvitegravir on human adipocytes: alterations in differentiation, gene expression and release of adipokines and cytokines. Antivir Res. 2016;132:59-65.

21. Villarroya J, Diaz-Delfin J, Hyink D, Domingo P, Giralt M, Klotman PE, et al. HIV type-1 transgene expression in mice alters adipose tissue and adipokine levels: towards a rodent model of HIV type-1 lipodystrophy. Antivir Ther. 2010;15:1021-8. 